\title{
More Than Meets the Eye: A Canadian Comparative Study on PowerPoint Use Among Post-Secondary Students With and Without Disabilities
}

\author{
Catherine S. Fichten ${ }^{1,2,3,4}$, Mary Jorgensen ${ }^{2}$, Alice Havel $^{1,2}$, Laura King ${ }^{2,5}$, Maegan Harvison ${ }^{2}$, Alex Lussier ${ }^{2,5}$ \& Eva \\ Libman $^{3,4}$ \\ ${ }^{1}$ Dawson College - Montreal, Canada \\ ${ }^{2}$ Adaptech Research Network, Montreal, Canada \\ ${ }^{3}$ McGill University, Montreal, Canada \\ ${ }^{4}$ Jewish General Hospital, Montreal, Canada \\ ${ }^{5}$ Cégep André-Laurendeau, Montreal, Canada \\ Correspondence: Catherine Fichten, 3040 Sherbrooke West, Montreal QC Canada H3Z 1A4, Canada. Tel: \\ 1-514-931-8731 x1546. E-mail: catherine.fichten@mcgill.ca
}

Received: June 12, 2019

doi:10.5430/irhe.v4n2p25
Accepted: June 21, 2019

Online Published: June 22, 2019

URL: https://doi.org/10.5430/irhe.v4n2p25

\begin{abstract}
The present study set out to explore effective teaching techniques using PowerPoint for post-secondary students with disabilities by comparing their views to those of students without disabilities. 284 Canadian post-secondary social science students, 75 of whom self-reported a disability, were surveyed about what aspects of PowerPoint use helps them learn. The good news is that the results indicate many similarities between the views of students with and without disabilities. Although all students felt that having PowerPoint available online was highly desirable, for students with disabilities this was perceived as an important disability accommodation. All students preferred that PowerPoint slides be made available before class in both PowerPoint and PDF formats; however, this was particularly important to students with disabilities. All students preferred that professors walk around some of the time rather than simply stand beside the lectern, that they select slides with good contrast rather than an interesting but busy background template, that they write concepts in full sentences as opposed to key words only, and that PowerPoint images be accompanied by text rather than presenting images only. Overall, our findings show that well-designed PowerPoint slides which incorporate accessibility features (easily included by using the Accessibility Checker feature of PowerPoint) can benefit everyone. Notably, fewer than half $(41 \%)$ of the students with disabilities had registered with the college to receive disability-related accommodations; therefore, it is important that PowerPoint, as used by professors, be accessible to this large segment of the population of students with disabilities. Informative slides with a clear template and good contrast, along with an engaging presentation style, are likely to benefit everyone. Our findings also show that, contrary to the fears of many educators, students are unlikely to miss class if slides are posted online. Moreover, this is equally true for academically stronger as well as weaker students.
\end{abstract}

Keywords: PowerPoint, post-secondary students with disabilities, registration for campus access services, disability, college university

\section{Introduction}

PowerPoint has been the mainstay of post-secondary teaching for over 20 years. As a result, there is now an extensive literature that examines which features of PowerPoint are particularly useful in post-secondary teaching and learning. Most of these studies appeared about a decade ago (e.g., Apperson, Laws, \& Scepansky, 2008; Berk, 2012; Brock \& Joglekar, 2011; Hill, Arford, Lubitow, Smollin, 2012; James, Burke, \& Hutchins, 2006). More recent articles typically focus on the use of PowerPoint in specific courses (e.g., Ankad et al., 2015) or in different countries (e.g., Alkash \& Al-Dersi, 2013; Inoue-Smith, 2016; Ögeyik, 2017; Yee, Sim, Ng, Low, \& Chong, 2017).

What is less well known is what aspects of PowerPoint are particularly useful, or possibly problematic, for students with disabilities. Most recent articles simply point out accessibly difficulties for students with specific impairments. 
For example, Taylor (2016) used the Universal Design for Instruction paradigm (cf. McGuire, Scott, \& Shaw, 2006) to discuss difficulties with PowerPoint. He noted that, when relied upon as class lecture notes made available to students, visual-presentation tools such as PowerPoint, work poorly with screen readers and magnifiers; however, this can be avoided by running the PowerPoint Accessibility Checker. Similar accessibility issues are raised by others, ranging from limitations of PowerPoint that lacks alt-tagging (Roth, Pure, Rabinowitz, \& Kaufman-Scarborough, 2018) to the absence of text descriptions for charts and tables in PowerPoint slides (Goodrich, 2016). Of course, if students are not provided with PowerPoint ahead of class, those who cannot see the often tiny fonts projected, those who need to prepare for the class ahead of time, and those who require screen reading or screen magnification software, can have serious difficulties.

\subsection{Access to Posted PowerPoint Online and Students With Disabilities}

When PowerPoint is provided to students, there are many benefits. For example, it has been shown that students had less need for note-taking services when universally accessible PowerPoint slides were available (Couzens et al., 2015). However, it has also been noted that tools like PowerPoint can be a "daunting barrier" when lecturers refuse to provide students with early access to course slides (Díez, Gavira, \& Molina, 2015). This last point had already been mentioned as long as 20 years ago by authors such as Fuller and her colleagues (Fuller, Bradley, \& Healey, 2004; Fuller, Healey, Bradley, \& Hall, 2004) and Holloway (2001), who noted that "while students with disabilities tend to request lecture notes in advance and in digital formats, lecturers rarely accede" (p. 156). More recently, Strnadová, Hájková, and Květoňová (2015) found in their study that, "a frequently mentioned problem was the refusal of lecturers to provide students with lecture PowerPoint slides or handouts" (p. 1085). MacCullagh, Bosanquet, and Badcock (2017) specified that for students with dyslexia "it was especially helpful when lecture slides or notes were made available in Microsoft PowerPoint or Word format rather than PDF, so they could be more easily manipulated" (p. 8). Sometimes, faculty deal with this issue by providing PowerPoint only to students with disabilities as an accommodation, but not to other students.

\subsection{Reasons Why PowerPoint Is Not Posted Online}

A common reason cited for not posting PowerPoint online or making it available to students is the widely held belief by faculty that students will not come to class. Findings reporting students skipping classes because of online resources, such as the availability of PowerPoint slides has, indeed, been reported (Traphagan, Kucsera, \& Kishi, 2010). However, the literature on this topic is mixed, with some studies showing that students are less likely to attend classes when PowerPoint slides are made available to them and other studies showing that this is not the case. For example, Bowman's (2009) and Worthington and Levasseur's (2015) experiments, which used attendance tracking, both showed that there was no difference in attendance between course sections where PowerPoint slides were and were not provided. The literature is further confounded by differences in who is being surveyed, professors or students, and by the methodology used: self-reports or actual behavior. For this reason, and for many others, the question of how this ubiquitous teaching tool in postsecondary education can be optimized to best serve students both with and without disabilities, remains to be explored more fully.

\subsection{Present Study}

The goal of the present investigation was to learn more about how PowerPoint is - or could - best be used to help students succeed. We compared the views of students with and without disabilities in the context of the following hypotheses.

Hypothesis 1. All students would find PowerPoint slides posted online useful. Students with disabilities would find it more useful than students without disabilities if PowerPoint slides are made available online before each class, as opposed to after the class.

Hypothesis 2. All students would find it more useful if PowerPoint slides are made available in both PPT and PDF formats as opposed to either PPT only or PDF only, since PPT format can be manipulated. However, students with disabilities would find this more useful than their counterparts without disabilities.

Hypothesis 3. Students with disabilities, compared to students without disabilities, would find it more useful if the professor stood beside the lectern when lecturing rather than walking around because this would result in less distraction and would help students who are speech (lip) reading the professor.

Hypothesis 4. Although all students would find this useful, students with disabilities, compared to students without disabilities, would find it more useful if slides had good contrast as opposed to an interesting/busy background template. 
Hypothesis 5. Students with disabilities, compared to students without disabilities, would find it more useful if slides had concepts written in full sentences as opposed to only having the key words of the concepts presented.

Hypothesis 6. Although all students would find it useful if images in PowerPoint had accompanying text rather than no text, students with disabilities, would find this more useful compared to students without disabilities.

\section{Procedure}

\subsection{Participants}

Participants were 284 social science students (213 females, 62 males, and 9 who specified a different gender status or preferred not to say) enrolled in nine psychology courses at a large metropolitan junior/community college. They were participating in a larger study of technology in teaching practices. All had completed at least one semester of studies (mean $=3.18, \mathrm{SD}=1.52$ ). Two-hundred and nine participants reported no disability (156 females, 46 males, and 7 who specified a different gender status or preferred not to say); 75 (26\%) self-reported at least 1 disability (57 females, 16 males, and 2 who specified a different gender status or preferred not to say). There was no significant gender difference between students with and without disabilities, $X^{2}=3,284=5.45, p=.142$.

\subsection{Measures}

\subsubsection{Demographic Questions}

These included gender, age, number of semesters completed, self-reported disability, "R" score (a standardized measure of grades) and whether the student had registered with the college's access services for students with disabilities.

\subsubsection{Disability Self-Definition}

Participants were asked, "Indicate which of the following apply to you (you can select more than one)."

- Totally blind

- Visual impairment (NOT adequately corrected by wearing glasses or contact lenses)

- Deaf

- Hard of hearing / hearing impairment

- Speech / communication impairment

- Learning disability (LD) (e.g., dyslexia)

- Attention deficit hyperactivity disorder (ADHD)

- Mobility impairment: wheelchair / scooter user

- Mobility impairment: use of a cane / crutch / walker

- Limitation in the use of hands / arms

- Chronic medical / health problem (e.g., diabetes, Crohn's)

- Mental illness /Psychological disorder (e.g., depression)

- Neurological impairment (e.g., epilepsy, traumatic brain injury)

- Autism spectrum disorder (e.g., autism, Asperger's)

- Other (please specify)

\section{- I do not have any of the above}

\subsubsection{Registration for Campus Disability-Related Services}

Participants were asked whether they were registered with the college's access center to receive accommodations related to a disability.

\subsubsection{PowerPoint Questionnaire for College Students}

This measure, which was available in regular print, large print and digital versions, contained two series of questions. One series of 5 questions dealt with students' overall experiences with PowerPoint; this used 6-point Likert scaling $(1=$ strongly disagree, $6=$ strongly agree). The second series consisted of 14 questions related to how well specific PowerPoint features helped students learn and were concerned with PowerPoint use in class, posting of PowerPoints, 
PowerPoint visual characteristics, and student engagement. These used 10-point Likert-type scaling: "On a scale of 0 to 10 , how well has this worked to help you learn? $0=$ very problematic, $10=$ very helpful".

\subsection{Procedure}

During the 2018 spring semester we administered regular and large print versions of an information and consent form along with the measures described above. Response rate was over 95\%. The protocol was approved by the college's Research Ethics Board. We informed students that digital versions of the documents were available, but no one requested this. All students were offered the chance to participate in a draw for an Android tablet.

\section{Results}

\subsection{Student Characteristics}

Seventy-five students (26\%) self-reported a disability and 209 (74\%) did not. Only $30(41 \%)$ of those reporting a disability had registered to receive disability related services; 44 (59\%) had not. Table 1 shows the disabilities of those who did and those who did not register for access services. It is evident that the most common disabilities of students were mental illness followed by a learning disability, attention deficit hyperactivity disorder, and chronic health problems. Among these disability groups, only students with a learning disability, or a visual or a hearing impairment were likely to register for access services.

Table 1. Frequency of disabilities - registered and not registered for access services

\begin{tabular}{lccccc}
\hline & Total & \multicolumn{2}{c}{ Registered } & \multicolumn{2}{c}{ Not Registered } \\
\cline { 3 - 6 } & $\mathrm{n}$ & $\mathrm{n}$ & $\%$ & $\mathrm{n}$ & $\%$ \\
\hline Mental illness & 38 & 8 & $21 \%$ & 30 & $79 \%$ \\
Learning disability & 15 & 10 & $67 \%$ & 5 & $33 \%$ \\
ADHD & 13 & 5 & $38 \%$ & 8 & $62 \%$ \\
Chronic health problems & 10 & 2 & $20 \%$ & 8 & $80 \%$ \\
Neurological impairment & 6 & 3 & $50 \%$ & 3 & $50 \%$ \\
Visual impairment & 3 & 3 & $100 \%$ & 0 & $0 \%$ \\
Hearing impairment & 3 & 1 & $33 \%$ & 2 & $67 \%$ \\
Speech / communication impairment & 1 & 1 & $100 \%$ & 0 & $0 \%$ \\
\hline
\end{tabular}

Note. Students could indicate as many disabilities as applied to them. $76 \%$ of the 75 students who self-reported a disability had a single disability, and $24 \%$ had more than one disability.

Table 2 shows that there was no significant difference between students with and without disabilities on age, number of semesters completed, or "R" score.

Table 2. Students with vs students without disabilities compared on age, semesters completed and "R" Score

\begin{tabular}{|c|c|c|c|c|c|c|c|c|}
\hline \multirow{2}{*}{ Measures } & \multicolumn{2}{|c|}{ With Disabilities } & \multicolumn{3}{|c|}{ Without Disabilities } & \multicolumn{3}{|c|}{ Test } \\
\hline & Mean & $S D$ & Mean & $S D$ & $T$ & $d f$ & $p=$ & $d$ \\
\hline Age & 18.79 & 7.71 & 18.45 & 1.71 & 1.84 & 280 & .067 & 0.06 \\
\hline Semesters completed & 3.18 & 1.71 & 3.02 & 1.55 & 0.73 & 277 & .466 & 0.10 \\
\hline "R" score & 24.98 & 3.68 & 26.14 & 3.55 & 1.94 & 186 & .054 & 0.32 \\
\hline
\end{tabular}




\subsection{Students' Overall Experiences With PowerPoint}

A multivariate analysis of variance approached significance, $F(5,233)=2.23, p=.052$. Therefore, we present the univariate analysis of variance (ANOVA) results in Table 3. These show that there were no significant differences between groups on questions regarding the overall usefulness of PowerPoint.

Table 3. Students' overall experiences with PowerPoint

\begin{tabular}{|c|c|c|c|c|c|c|c|c|}
\hline & \multicolumn{2}{|c|}{$\begin{array}{c}\text { Students with } \\
\text { Disabilities }\end{array}$} & \multicolumn{2}{|c|}{$\begin{array}{l}\text { Students Without } \\
\text { Disabilites }\end{array}$} & \multirow[b]{2}{*}{$t$} & \multirow[b]{2}{*}{$d f$} & \multirow[b]{2}{*}{$p=$} & \multirow[b]{2}{*}{$d$} \\
\hline & $M$ & $S D$ & $M$ & $S D$ & & & & \\
\hline Instructors use PPT in a $\mathrm{v}$ & 5.09 & 0.79 & 5.01 & 0.75 & 0.77 & 280 & 0.444 & 0.10 \\
\hline Instructors make PPTs available to me online & 4.40 & 1.20 & 4.62 & 1.07 & 1.48 & 281 & 0.139 & 0.19 \\
\hline I am more likely to miss class if PPT posted online & 2.73 & 1.40 & 2.84 & 1.51 & 0.54 & 281 & 0.589 & 0.08 \\
\hline PPT is accessible to me, regardless of my disabilities/needs & 5.01 & 1.22 & 5.26 & 1.04 & 1.59 & 254 & 0.112 & 0.22 \\
\hline PPT is accessible on Apple device & 5.19 & 1.19 & 5.51 & 0.88 & 2.28 & 247 & 0.053 & 0.31 \\
\hline
\end{tabular}

Note . Range of scores is $1=$ strongly disagree to $6=$ strongly agree.

The results also show that, overall, students felt that PowerPoint, as used by their professors, was generally accessible on their Apple device, that professors used PowerPoint in a way that helped them learn, and that PowerPoint is available to students regardless of their specific disabilities or needs. Students were slightly less likely to agree that PowerPoint is made available to them online and, as illustrated in Figure 1,67\% of students disagreed with the statement that they were likely to miss class if PowerPoint slides are posted online.

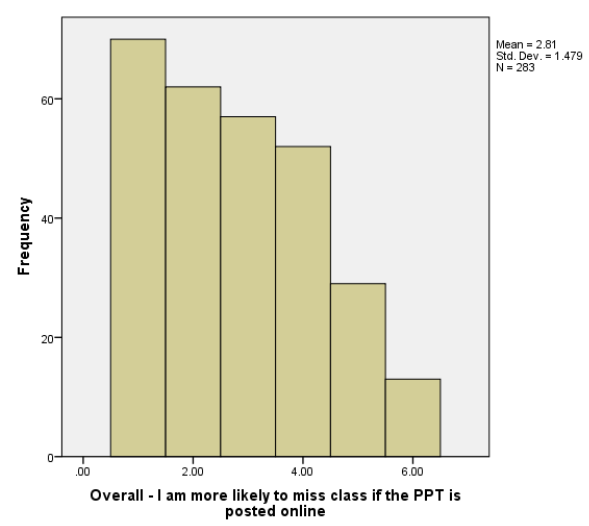

Figure 1. Frequency of missing class when PowerPoint is posted online

Figure 1. Level of agreement with the statement that the student is more likely to miss class if PowerPoint slides are posted online. Lower scores indicate disagreement with the statement.

We also compared responses to the question, "Overall, I am more likely to miss class if the PowerPoint is posted online" for academically stronger students (i.e., whose "R" score was above the median ("R" $\Rightarrow 25.5$ )) and academically weaker students (i.e., whose "R" score was below the median ("R" $<25)$ ). Results indicate no significant differences for either students with, $\mathrm{t}(46)=.58, \mathrm{p}=.263$ or without disabilities, $\mathrm{t}(137)=.55, \mathrm{p}=.585$.

Correlations among the five items which deal with students' overall experiences with PowerPoint are shown below. These indicate significant relationships between use of PowerPoint in a way that helps students learn and the availability of PowerPoint online for both students with and without disabilities. Similarly, availability of PowerPoint online is significantly related to the accessibility of PowerPoint regardless of students' needs/disabilities. 
The relationship between the accessibility of PowerPoint on an Apple device was significantly related both to helping students learn and to the accessibility of PowerPoint regardless of students' needs, but only for students without disabilities.

The accessibility of PowerPoint to students regardless of their needs/disabilities and the use of PowerPoint in a way that helps students learn had the highest correlation coefficient for students with disabilities.

Table 4. Correlations between the overall experiences of students with and without disabilities

\begin{tabular}{lllll}
2 Overall, my instructors make the PowerPoints available to me online & $.164^{*}$ & -0.202 & $.426^{* *}$ & 0.24 \\
3 Overall, I am more likely to miss class if the PowerPoint is posted online & -0.088 & -0.02 & -0.127 & -0.055 \\
4 Overall, PowerPoint is accessible to me, regardless of my specific needs/disabilities & 0.085 & $.249^{* *}$ & 0.109 & 0.158 \\
5 Overall, PowerPoint is accessible to me when I use an Apple device & $.176^{*}$ & 0.004 & 0.095 & $.167^{*}$ \\
\hline
\end{tabular}

* Correlation is significant at the 0.05 level (2-tailed).

** Correlation is significant at the .01 level (2-tailed).

Note. Students with disabilities above the diagonal, students without disabilities below the diagonal

\subsection{Results Related to the Hypotheses Based on the PowerPoint Questionnaire for College Students}

Hypothesis 1. We predicted that all students would find it useful if PowerPoint slides were posted online, but that students with disabilities, compared to students without disabilities, would find it most useful if PowerPoint slides were made available online before each class, as opposed to after the class. Means in Table 5 and ANOVA results show a significant difference between PowerPoint posting time, with PowerPoint being posted online before the class having the best and PowerPoint never being posted online having the worst evaluation, $F(2,360)=316.54, p<.001$. There was no significant group effect, $F(1,180)=1.89, p=.171$, although the interaction of group x posting time approached significance, $F(2,360)=2.84, p=.061$. Means in Table 5 suggest that PowerPoint posted online before class was rated more favorably than PowerPoint posted online after class by students with disabilities compared to students without disabilities.

Table 5. Preferences for when PowerPoints are posted online for students with and without disabilities

\begin{tabular}{llrr}
\hline When PowerPoint posted & \multicolumn{1}{c}{ Group } & $M$ & $S D$ \\
\hline PowerPoint never posted online & Students with disabilities & 1.12 & 2.46 \\
& Students without disabilities & 0.97 & 1.76 \\
PowerPoint posted online after class & Students with disabilities & 6.13 & 3.16 \\
& Students without disabilities & 7.22 & 2.54 \\
PowerPoint posted online before class & Students with disabilities & 7.77 & 2.62 \\
& Students without disabilities & 7.75 & 2.48 \\
\hline
\end{tabular}

In Hypothesis 2 we predicted that although all students would find this useful, students with disabilities, compared to students without disabilities, would find it more useful if PowerPoint slides were made available in both PowerPoint and PDF formats as opposed to either PowerPoint or PDF only. Results in Table 6 and the statistical test results show a significant format main effect, $F(2,170)=30.63, p<.001$, indicating that students, in general, prefer that PowerPoint slides be posted in both PowerPoint and PDF formats and that they least preferred PDF only. The group main effect was not significant, $F(1,85)=.26, p=.61$, although the interaction of group $\mathrm{x}$ format was, $F(2,170)=4.36$, $p<.014$. The means in Table 6 suggest that students with disabilities liked PDF only the least. 
Table 6. Preference for the format in which PowerPoints are posted online for students with and without disabilities

\begin{tabular}{llrr}
\hline Format of PowerPoint & \multicolumn{1}{c}{ Group } & $M$ & $S D$ \\
\hline PowerPoint and PDF posted online & Students with disabilities & 8.50 & 2.31 \\
& Students without disabilities & 8.19 & 2.12 \\
Only PowerPoint format posted online & Students with disabilities & 7.60 & 1.85 \\
& Students without disabilities & 7.21 & 2.10 \\
Only PDF posted online & Students with disabilities & 5.00 & 3.20 \\
& Students without disabilities & 6.40 & 2.75 \\
\hline
\end{tabular}

Hypothesis 3 predicted that students with disabilities, compared to students without disabilities, would find it more useful if the professor stood beside the lectern while lecturing rather than walking around. This hypothesis was not confirmed, as means in Table 7 and statistical test results show that both groups significantly preferred that the professor walk around rather than stand beside the lectern, $F(1,211)=18.10, p<.001$. Although the group effect approached significance, $F(1,211)=3.88, p=.050$, showing that ratings of students with disabilities were lower than those of students without disabilities, the interaction was not significant $F(1,211)=.60, p=.438$.

Table 7. Preference for professor walking around or not while teaching for students with and without disabilities

\begin{tabular}{llcc}
\hline Professor movement & Group & $M$ & $S D$ \\
\hline Professor stands beside computer & Students with disabilities & 5.71 & 2.71 \\
& Students without disabilities & 6.49 & 2.81 \\
Professor walks around & Students with disabilities & 7.17 & 2.27 \\
& Students without disabilities & 7.50 & 2.55 \\
\hline
\end{tabular}

In Hypothesis 4 we predicted that although all students would find this useful, students with disabilities, compared to students without disabilities, would find it more useful if slides had good contrast as opposed to an interesting/busy background template. Test results and means in Table 8 show that students generally preferred good contrast in PowerPoint as opposed to an interesting/busy background, $F(1,170)=78.33, p<.001$. Neither the group effect $F$ $(1,170)=.07, p=.788$, nor the interaction, $F(1,170)=.75, p=.388$ was significant.

Table 8. Preference for contrast between background and text for students with and without disabilities

\begin{tabular}{llcc}
\hline Contrast of PowerPoint slides & \multicolumn{1}{c}{ Group } & $M$ & $S D$ \\
\hline $\begin{array}{l}\text { PowerPoint slides have good contrast between background and } \\
\text { text }\end{array}$ & Students with disabilities & 7.51 & 2.52 \\
& Students without disabilities & 7.66 & 2.45 \\
& & 5.26 & 3.00 \\
PowerPoint slides have interesting/busy background template & Students with disabilities & 4.91 & 2.91 \\
\hline
\end{tabular}


Hypothesis 5 predicted that students with disabilities, compared to students without disabilities, would find it more useful if slides had concepts written in full sentences as opposed to only having key words/concepts. Means in Table 9 and statistical test results show a significant PowerPoint content main effect, $F(1,245)=30.50, p<.001$, with students preferring concepts written in full sentences. Neither the group main effect, $F(1,245)=.87, p=.352$, nor the interaction was significant, $F(1,245)=.52, p=.473$.

Table 9. Preference for content on PowerPoint slides

\begin{tabular}{llrr}
\hline Content of PowerPoint slides & \multicolumn{1}{c}{ Group } & $M$ & $S D$ \\
\hline Only key words/concepts are presented on PowerPoint slides & Students with disabilities & 5.84 & 3.28 \\
& Students without disabilities & 5.36 & 2.99 \\
PowerPoint slides have concepts written in full sentences & Students with disabilities & 7.28 & 2.73 \\
& Students without disabilities & 7.38 & 2.50 \\
\hline
\end{tabular}

In Hypothesis 6 we predicted that although all students would find this useful, students with disabilities, compared to students without disabilities, would find it more useful if images in PowerPoint had text to go along with them rather than no text. Means in Table 10 and test results show a significant PowerPoint content effect, $F(1,159)=252.54$, $p<.001$, with students preferring that PowerPoint slides have text with images as opposed to images only. Neither the group main effect, $F(1,159)=.76, p=.386$, nor the interaction was significant, $F(1,159)=.00, p=.993$.

Table 10. Preference for images with or without text for students with and without disabilities

\begin{tabular}{llrr}
\hline Text or no text with images in PowerPoint & Group & $M$ & $S D$ \\
\hline $\begin{array}{l}\text { Only images/graphs are presented on PowerPoint slides }- \\
\text { no text }\end{array}$ & Students with disabilities & 3.16 & 2.99 \\
& Students without disabilities & 2.86 & 2.63 \\
& & & \\
PowerPoint slides have text and images/graphs & Students with disabilities & 8.07 & 2.51 \\
& Students without disabilities & 7.78 & 2.40 \\
\hline
\end{tabular}

\section{Discussion}

The good news is that, overall, the results indicate that good teaching practice using PowerPoint for students with and without disabilities is very similar. The findings show that students perceived that professors used PowerPoint in a way that helped them learn, that PowerPoint is usually available to students whatever their disabilities or needs, and that it was generally accessible on Apple devices.

Consistent with findings of many others (e.g., Diez, Gavira, \& Molina, 2015; Fuller, Bradley, \& Healey, 2004; Fuller, Healey, Bradley, \& Hall, 2004), students indicated that it is particularly useful that PowerPoint slides be made available online. They preferred that this be done before rather than after class and students with and without disabilities perceived that such posting was helpful in their learning process. Students with disabilities, saw this as the equivalent of a disability-related accommodation.

With respect to the timing of PowerPoint posting online and classroom attendance, our findings indicate that 2/3 of our sample indicated that they would not miss class if PowerPoint slides are posted online. Our results, based on self-ratings, are consistent with attendance tracking findings in the literature (e.g., Bowman, 2009; Worthington et al., 2015). Moreover, this was true in our sample for both students who were academically strong and weak. 


\subsection{Similarities and Differences Between Students With and Without Disabilities}

We formulated six hypotheses related to differences between students with and without disabilities. Although in most cases views of students with and without disabilities were similar, some differences emerged.

For example, we expected (Hypothesis 1) that all students would find it useful if PowerPoint slides were posted online and we also expected that students with disabilities would find it especially useful if PowerPoint slides were made available online before rather than after class. Hypothesis 1 was confirmed, as all students wanted PowerPoint slides to be posted, especially before rather than after class. However, this was particularly important for students with disabilities. As highlighted by MacCullagh, Bosanquet, and Badcock (2017), many students, especially those with learning disabilities, prefer to study the PowerPoint slides before class because of difficulty following lecture slides during class. This is also likely for students whose first language is not the language of instruction.

In Hypothesis 2 we again predicted that although all students would find this helpful, students with disabilities would find it especially useful if PowerPoint slides were made available in both PowerPoint and PDF formats. The results confirm this prediction. While all students preferred that PowerPoint slides be posted in both PowerPoint and PDF formats, students with disabilities were least likely to want PDF format only. As MacCullagh, Bosanquet, and Badcock (2017) pointed out, PPT format allows students to manipulate the content of the slides.

In Hypothesis 3 we predicted that students with disabilities would be less likely to prefer that the professor stand beside the lectern as opposed to walking about while making a PowerPoint presentation. However, we found no significant differences between students with and without disabilities. This may be due to the nature of our sample of students with disabilities, since only three participants had a hearing impairment and it would have been these students whom we expected to prefer that the professor stand still so they can speech read (lip read) more easily. Nevertheless, this may have been overshadowed by what Selwyn (2016) called "Death by PowerPoint," a phenomenon related to lack of student engagement due to professors simply reading from the slides.

We also predicted (Hypothesis 4) that students with disabilities would find good contrast to be much more important than an interesting/busy template. Contrary to expectation, all students strongly preferred good contrast and students with disabilities did not differ from students without disabilities. Perhaps students have become habituated to PowerPoint presentations and have come to value clear text that they can easily read.

Hypotheses 5 and 6 were concerned with preference for slides with full sentences as opposed to simply key words or concepts, and with images and graphs on PowerPoint slides with or without text. Hypotheses related to differences between students with and without disabilities were not confirmed, as all students preferred full sentences and slides with graphs that also had text.

Some of our results may be due to the nature of our sample of students with disabilities, as there were few students with visual, hearing or mobility impairments. Instead, most of our sample of students with disabilities had non-visible disabilities, with mental illness being most common. Moreover, 59\% of our sample - and $79 \%$ of students with mental illness - had not registered with the college's access services for any disability accommodations.

Nevertheless, as Moriña (2017) noted, universal design benefits all students, whether they have a disability or not. Well-designed PowerPoint slides which incorporate accessibility features (these can be easily included by using the Accessibility Checker feature of PowerPoint) can benefit everyone. Posting PowerPoint in both PowerPoint and PDF formats before class is not likely to interfere with attendance according to our data and that of other studies. Informative slides with a clear template and good contrast, along with an engaging presentation style, are likely to benefit everyone.

\section{Limitations}

Even though our sample was relatively large and encompassed nine different courses, our investigation relies on social science students in a single junior/community college. In addition, participants self-reported their disabilities.

\section{Conclusions, Implications and Recommendations}

Future research should include a more diverse sample of students and should include more objective measures of functioning. Sampling of students with disabilities should either include visual, hearing, mobility and mental health impairments and learning disabilities in sufficient numbers to compare specific views related to PowerPoint or limit the sampling of students with disabilities to one disability grouping at a time, to highlight individual differences.

While an original intention of the present investigation was to identify specific needs and preferences among students with disabilities, the results of the study indicate that good teaching practice using PowerPoint for students 
with and without disabilities is very similar. Well-designed PowerPoint slides can benefit all types of learners. When professors design PowerPoints that incorporate good practice and accessibility features, they are very likely responding to the needs of a larger number of students than they may have anticipated.

Contrary to the present findings, but according to the literature, many professors believe that students will not come to class if the PowerPoints are made available to them. Faculty could address their concerns regarding attendance in several ways. Professors might initiate a discussion with students regarding the importance of class attendance. (Of course, it is understandable that students would not be motivated to attend class if the professor merely reads the PowerPoint slides aloud verbatim). Students could also be made aware that the course content for which they would be responsible goes beyond the PowerPoints and includes class discussions and activities, audiovisual material, class presentations, etc.

Students with disabilities, especially those with mental illness and chronic health problems, often find attending class on a regular basis to be a challenge. Access to PowerPoint notes is one means of keeping up with the class in a more objective way than relying on a note-taker, which can also be costly and not always easy to find.

If students can use their mobile devices during the class to view the uploaded PowerPoint, they may be better able to see the slides as well as take notes. Having access to the PowerPoint before the class can also encourage note taking which 'enhances' the professor's material as opposed to note taking without any visual support. Perhaps students' preference for concepts written in full sentences, as opposed to only having key words, is related to their note-taking and exam-preparation concerns.

To address apprehension regarding lack of student engagement due to overuse or poor use of PowerPoint some faculty have turned to using interesting background templates and animations. However, students instead prefer good contrast on slides. Students also liked it when professors walked around rather than stood beside the lectern. This could be related to students wanting their professors to interact with them rather than simply to read the slides. These findings imply that in spite of the benefits of PowerPoint, faculty need to get students actively involved in the learning process - something which is important for all students, but perhaps more critical for students with attentional problems.

The following recommendations for professors strongly reflect the findings of the present research, particularly in regard to students with disabilities.

1) Provide PowerPoints online before class.

2) Make PowerPoint slides available in both PowerPoint and PDF formats.

3) Incorporate accessibility features by using the Accessibility Checker feature of PowerPoint.

4) Walk around some of the time rather than stand beside the lectern.

5) Select a good contrast rather than an interesting but busy background template.

6) Write concepts in full sentences as opposed to key words only.

7) Accompany PowerPoint images with text rather than images only.

The recommendations above are based on the responses to specific questions that students with and without disabilities were asked regarding their experiences with PowerPoint. It can be assumed that students' needs may vary to some degree based on individual characteristics, subject matter, faculty teaching methods, etc. Disabilities also play a critical role in determining students' needs, but many students are reluctant to step forward and identify themselves as "disabled." Therefore, it might be beneficial for professors to make the effort to survey their students early in the semester to ascertain if the manner in which PowerPoints are being used in their teaching is helpful to both students with and without disabilities and whether, indeed, this ubiquitous post-secondary technology allows students to learn to their fullest potential.

\section{Acknowledgements}

This research was conducted with the help of an S024 grant awarded by Dawson College to Catherine Fichten.

\section{References}

Alkash, K. A. M., \& Al-Dersi, Z. E. M. (2013). Advantages of using PowerPoint presentation in EFL classroom and the status of its use in Sebha University. International Journal of English Language \& Translation Studies, 1(1), 3-16. Retrieved

from https://studylib.net/doc/8748362/advantages-of-using-powerpoint-presentation-in-efl---ij-elts 
Ankad, R. B., Shashikala, G. V., Herur, A., Manjula, R., Chinagudi, S., \& Patil, S. (2015). PowerPoint presentation in learning physiology by undergraduates with different learning styles. Advances in Physiology Education, 39(4), 367-371. https://doi.org/10.1152/advan.00119.2015

Apperson, J. M., Laws, E. L., \& Scepansky, J. A. (2008). An assessment of student preferences for PowerPoint presentation structure in undergraduate courses. Computers \& Education, 50(1), 148-153. https://doi.org/10.1016/j.compedu.2006.04.003

Berk, R. A. (2012). Top 10 evidence-based, best practices for PowerPoint in the classroom. Transformative Dialogues: Teaching \& Learning Journal, 5(3), 1-7. Retrieved from http://www.ronberk.com/articles/2012_best-practices.pdf

Bowman, L. L. (2009). Does posting PowerPoint presentations on WebCT affect class performance or attendance?. Journal of Instructional Psychology, 36(2), 104-107. Retrieved from http://eds.a.ebscohost.com/eds/pdfviewer/pdfviewer?vid=1\&sid=9901daf8-29b4-4edc-8063-5b540fe746a1\%40 sdc-v-sessmgr03

Brock, S., \& Joglekar, Y. (2011). Empowering PowerPoint: Slides and teaching effectiveness. Interdisciplinary Journal of Information, Knowledge, and Management, 6, 85-94. https://doi.org/10.28945/1366

Couzens, D., Poed, S., Kataoka, M., Brandon, A., Hartley, J., \& Keen, D. (2015). Support for students with hidden disabilities in universities: A case study. International Journal of Disability, Development and Education, 62(1), 24-41. https://doi.org/10.1080/1034912X.2014.984592

Díez, A. M., Gavira, R. L., \& Molina, V. M. (2015). Students with disabilities in higher education: A biographical-narrative approach to the role of lecturers. Higher Education Research \& Development, 34(1), 147-159. https://doi.org/10.1080/07294360.2014.934329

Fuller, M., Bradley, A., \& Healey, M. (2004). Incorporating disabled students within an inclusive higher education environment. Disability \& Society, 19(5), 455-468. https://doi.org/10.1080/0968759042000235307

Fuller, M., Healey, M., Bradley, A., \& Hall, T. (2004). Barriers to learning: A systematic study of the experience of disabled students in one university. Studies in Higher Education, 29(3), 303-318. https://doi.org/10.1080/03075070410001682592

Goodrich, M. A. (2016). Improving distance education for disabled students: Making the grade. Distance Learning, 13(1), 15-20.

Hill, A., Arford, T., Lubitow, A., \& Smollin, L. (2012). "I'm ambivalent about it": The dilemmas of PowerPoint. Teaching Sociology, 40(3), 242-256. https://doi.org/10.1177/0092055X12444071

Holloway, S. (2001). The experience of higher education from the perspective of disabled students. Disability \& Society, 16(4), 597-615. https://doi.org/10.1080/09687590120059568

Inoue-Smith, Y. (2016). College-based case studies in using PowerPoint effectively. Cogent Education, 3(1). https://doi.org/10.1080/2331186X.2015.1127745

James, K. E., Burke, L. A., \& Hutchins, H. M. (2006). Powerful or pointless? Faculty versus student perceptions of PowerPoint use in business education. Business Communication Quarterly, 69(4), 374-396. https://doi.org/10.1177/1080569906294634

MacCullagh, L., Bosanquet, A., \& Badcock, N. A. (2017). University students with Dyslexia: A qualitative exploratory study of learning practices, challenges and strategies. Dyslexia, 23(1), 3-23. https://doi.org/10.1002/dys. 1544

McGuire, J. M., Scott, S. S., \& Shaw, S. F. (2006). Universal design and its applications in educational environments. Remedial and Special Education, 27(3), 166-175. https://doi.org/10.1177/07419325060270030501

Moriña, A. (2017). Inclusive education in higher education: Challenges and opportunities. European Journal of Special Needs Education, 32(1), 3-17. https://doi.org/10.1080/08856257.2016.1254964

Ögeyik, M. C. (2017). The effectiveness of PowerPoint presentation and conventional lecture on pedagogical content knowledge attainment. Innovations in Education and Teaching International, 54(5), 503-510. https://doi.org/10.1080/14703297.2016.1250663 
Roth, D., Pure, T., Rabinowitz, S., \& Kaufman-Scarborough, C. (2018). Disability awareness, training, and empowerment: A new paradigm for raising disability awareness on a university campus for faculty, staff, and students. Social Inclusion, 6(4), 116-124. https://doi.org/10.17645/si.v6i4.1636

Selwyn, N. (2016). Digital downsides: Exploring university students' negative engagements with digital technology. Teaching in Higher Education, 21(8), 1006-1021. https://doi.org/10.1080/13562517.2016.1213229

Strnadová, I., Hájková, V., \& Květoňová, L. (2015). Voices of university students with disabilities: Inclusive education on the tertiary level - a reality or a distant dream? International Journal of Inclusive Education, 19, 1080-1095. https://doi.org/10.1080/13603116.2015.1037868

Taylor, M. A. (2016). Improving accessibility for students with visual disabilities in the technology-rich classroom. Political Science \& Politics, 49, 122-127. https://doi.org/10.1017/S1049096515001134

Traphagan, T., Kucsera, J. V., \& Kishi, K. (2010). Impact of class lecture webcasting on attendance and learning. Educational Technology Research and Development, 58(1), 19-37. https://doi.org/10.1007/s11423-009-9128-7

Worthington, D. L., \& Levasseur, D. G. (2015). To provide or not to provide course PowerPoint slides? The impact of instructor-provided slides upon student attendance and performance. Computers \& Education, 85, 14-22. https://doi.org/10.1016/j.compedu.2015.02.002 